\title{
Introduction of severe traumatic brain injury care protocol is associated with reduction in mortality for pediatric patients: a case study of Children's Healthcare of Atlanta's neurotrauma program
}

\author{
Andrew Reisner, MD, ${ }^{1-3}$ Joshua J. Chern, MD, PhD, ${ }^{1-3}$ Karen Walson, MD, ${ }^{3}$ Natalie Tillman, $R N,{ }^{3}$ \\ Toni Petrillo-Albarano, MD, ${ }^{1}$ Eric A. Sribnick, MD, ${ }^{4}$ Laura S. Blackwell, PhD, ${ }^{1,3}$ Zaev D. Suskin, BA, ${ }^{5}$ \\ Chia-Yi Kuan, MD, PhD, ${ }^{6}$ and Atul Vats, MD ${ }^{1}$ \\ Departments of ${ }^{1}$ Pediatrics and ${ }^{2}$ Neurosurgery, Emory University School of Medicine; ${ }^{3}$ Children's Healthcare of Atlanta, \\ Georgia; ${ }^{4}$ Department of Surgery, Nationwide Children's Hospital, Columbus, Ohio; ${ }^{5}$ Georgetown University School of Medicine, \\ Washington, DC; and 'Department of Neuroscience, University of Virginia School of Medicine, Charlottesville, Virginia
}

\begin{abstract}
OBJECTIVE Evidence shows mixed efficacy of applying guidelines for the treatment of traumatic brain injury (TBI) in children. A multidisciplinary team at a children's health system standardized intensive care unit-based TBI care using guidelines and best practices. The authors sought to investigate the impact of guideline implementation on outcomes. METHODS A multidisciplinary group developed a TBI care protocol based on published TBI treatment guidelines and consensus, which was implemented in March 2011. The authors retrospectively compared preimplementation outcomes (May 2009 to March 2011) and postimplementation outcomes (April 2011 to March 2014) among patients < 18 years of age admitted with severe TBI (Glasgow Coma Scale score $\leq 8$ ) and potential survivability who underwent intracranial pressure (ICP) monitoring. Measures included mortality, hospital length of stay (LOS), ventilator LOS, critical ICP elevation time (percentage or total time that ICP was $>40 \mathrm{~mm} \mathrm{Hg}$ ), and survivor functionality at discharge (measured by the WeeFIM score). Data were analyzed using Student t-tests.
\end{abstract}

RESULTS A total of 71 and 121 patients were included pre- and postimplementation, respectively. Mortality (32\% vs $19 \% ; p<0.001$ ) and length of critical ICP elevation (> $20 \mathrm{~mm} \mathrm{Hg} ; 26.3 \%$ vs $15 \% ; p=0.001$ ) decreased after protocol implementation. WeeFIM discharge scores were not statistically different (57.6 vs $58.9 ; p=0.9$ ). Hospital LOS (median 19.6 days; $p=0.68$ ) and ventilator LOS (median 10 days; $p=0.24$ ) were unchanged.

CONCLUSIONS A multidisciplinary effort to develop, disseminate, and implement an evidence-based TBI treatment protocol at a children's hospital was associated with improved outcomes, including survival and reduced time of ICP elevation. This type of ICP-based protocol can serve as a guide for other institutions looking to reduce practice disparity in the treatment of severe TBI.

https://thejns.org/doi/abs/10.3171/2018.2.PEDS17562

KEYWORDS traumatic brain injury; intracranial pressure monitoring; intensive care unit; practice guidelines; trauma

$\mathrm{T}$ RAUMATIC brain injury (TBI) is a major cause of morbidity and mortality in children., ${ }^{5,10}$ The extent of the primary injury, as measured by the Glasgow Coma Scale (GCS), is a major determinant of outcomes. Equally important are the secondary injuries that are due to the complex pathophysiological cascade resulting from the primary insult. ${ }^{1,717}$ This cascade includes secondary neuronal and cellular damage, cell membrane disruption, neurotransmitter dysfunction, impaired cellular metabolism, changes in cerebral blood flow dynam-

ABBREVIATIONS EVD = external ventricular drain; GCS = Glasgow Coma Scale; ICP = intracranial pressure; LOS = length of stay; TBI = traumatic brain injury . SUBMITTED October 10, 2017. ACCEPTED February 19, 2018.

INCLUDE WHEN CITING Published online May 25, 2018; DOI: 10.3171/2018.2.PEDS17562. 
ics, cerebral hypoxia, and inflammation in the central nervous system.

The goal of TBI care is to avoid or minimize the deleterious effects of secondary injuries. Several studies support coordinated management and implementation of practice guidelines to improve outcomes of patients with severe TBI. $8,15,17,22,24,26$ These care protocols may be effective because they lead to a decreased time interval of elevated intracranial pressure (ICP), a common secondary condition known to be associated with poor clinical outcomes., ${ }^{9,27}$

There is evidence in TBI, and across other clinical disciplines, that adherence to guidelines and best practices can improve outcomes. ${ }^{6,16,21,25}$ Yet practice variance is still seen in the treatment of pediatric TBI, including low adherence to recommendations for ICP monitoring. ${ }^{2,3,23}$ This variance is an important determinant in patient outcomes. ${ }^{12,13,19}$

In this study, we documented our experience in developing and implementing a severe TBI guideline at Children's Healthcare of Atlanta (Children's). The guideline was applicable to all trauma patients who sustained a severe TBI (GCS score $\leq 8)$. Patient outcomes before and after protocol guideline implementation were analyzed.

\section{Methods \\ Study Design}

The Internal Review Board at Children's approved this study. The study was retrospective in design and examined patients from two hospital campuses, which are both tertiary care centers with specialized pediatric ICUs.

The guideline was implemented in April 2011. An interrupted time series analysis enabled comparisons between patients admitted and treated during a preguideline period (May 2009 to March 2011) versus patients treated in a post-guideline implementation period (April 2011 to March 2014). Data were retrospectively collected from the electronic medical records and chart review.

Patients aged $<18$ years met inclusion criteria if they had a diagnosis of severe TBI (initial GCS score $\leq 8$ ), potential survivability, and had undergone placement of an ICP monitor. Placement of an ICP monitor initiated use of the severe TBI guideline.

Intracranial monitors were either a parenchymal electrode (Camino bolt; Integra LifeSciences) or an external ventricular drain (EVD) and monitoring system (Medtronic).

Patients were included only if the injury etiology was suspected to be one of blunt or penetrating trauma. Patients with suspected nontraumatic etiologies (e.g., infectious or anoxic brain injuries) were excluded. Additionally, children who were deemed to have irreversible, significant brain injury based on clinical and/or imaging findings (usually brainstem injuries) or significant comorbidities such that survival was not realistic were excluded. Cause of injury was not tracked.

\section{Guideline Development}

In 2009 a multidisciplinary committee was formed at Children's representing administration, neurosurgery, critical care, trauma surgery, rehabilitation, and nursing services, with the primary goal of improving the management of pediatric severe TBI. Recommendations from the national Guidelines for the Acute Medical Management of Severe Traumatic Brain Injury in Infants, Children, and Adolescents were used as a starting point. ${ }^{4}$ The guidelines were modified at quarterly meetings (e.g., nutrition consult and more vigilant platelet factor monitoring), based on evidence when available and consensus when not. Compliance was continually monitored and frequent education seminars were held. Baseline use of ICP monitoring in 2010 was at a rate of $34.2 \%$. The severe TBI guideline was implemented in March 2011, from which point 100\% compliance was reached. Steps were taken to ensure $100 \%$ compliance, including having the guideline passed by Children's Medical Executive Committee, which mandated that all involved with care of severe TBI used this guideline. Furthermore, the Children's Quality Department was involved in the study and tracked compliance monthly, requesting written information for any deviation from compliance. Usage of the severe TBI guideline became a tracked quality parameter of the neurosurgery department.

Treatment algorithms were digitized in computerized order sets (EPIC). The guideline is a three-tier, stepwise method for treating elevated ICP (Figs. 1 and 2). For patients with GCS scores $\leq 8$, a Camino bolt and/or an EVD was placed, the patient was intubated, and $\mathrm{PaCO}_{2}$ was maintained between 23 and $45 \mathrm{~mm} \mathrm{Hg}$. Labs (complete blood chemistry, basic metabolic profile, and a disseminated intravascular coagulation panel) were drawn every 6 hours for 48 hours. The patient's head of bed was positioned at $30^{\circ}$, normothermia $\left(36^{\circ} \mathrm{C}-37.5^{\circ} \mathrm{C}\right)$ was maintained, and orders for a patient nutrition consult were placed on hospital day 1 .

While ICPs were recorded on an hourly basis, if the ICU nurse noted that the ICP was elevated, steps were taken immediately, including making sure the head of the bed was elevated $30^{\circ}$, ensuring the head was midline, and recalibrating the monitor. If ICP was sustained above 20 $\mathrm{mm} \mathrm{Hg}$ for more than 5 minutes, sedation and analgesia were the first-line therapies, followed by ventriculostomy drainage, if needed.

If ICP was unresponsive to phase I treatments, phase II was initiated. Cerebral perfusion pressure was maintained $>40 \mathrm{~mm} \mathrm{Hg}$ for infants and $>50 \mathrm{~mm} \mathrm{Hg}$ for patients older than 1 year of age. Second-tier medical therapies included either neuromuscular blockade or hyperosmolar therapy with either 3\% saline or mannitol. If these therapies were unsuccessful, barbiturate therapy with induction of a pentobarbital coma (and continuous EEG monitoring) was initiated.

Patients with ICP unresponsive to the aforementioned treatments would receive mild hyperventilation with the goal of a $\mathrm{PaCO}_{2}$ between 30 and $35 \mathrm{~mm} \mathrm{Hg}$ and a mandatory repeat head CT scan. If ICPs were persistently elevated, despite the aforementioned therapies, alternative treatments could then be considered by the clinicians (e.g., moderate hypothermia to a goal temperature of $32^{\circ} \mathrm{C}-$ $\left.34^{\circ} \mathrm{C}\right)$.

In addition, panic values were defined, including ICP $\geq$ $40 \mathrm{~mm} \mathrm{Hg}$, pupillary changes (e.g., unilateral, unreactive 


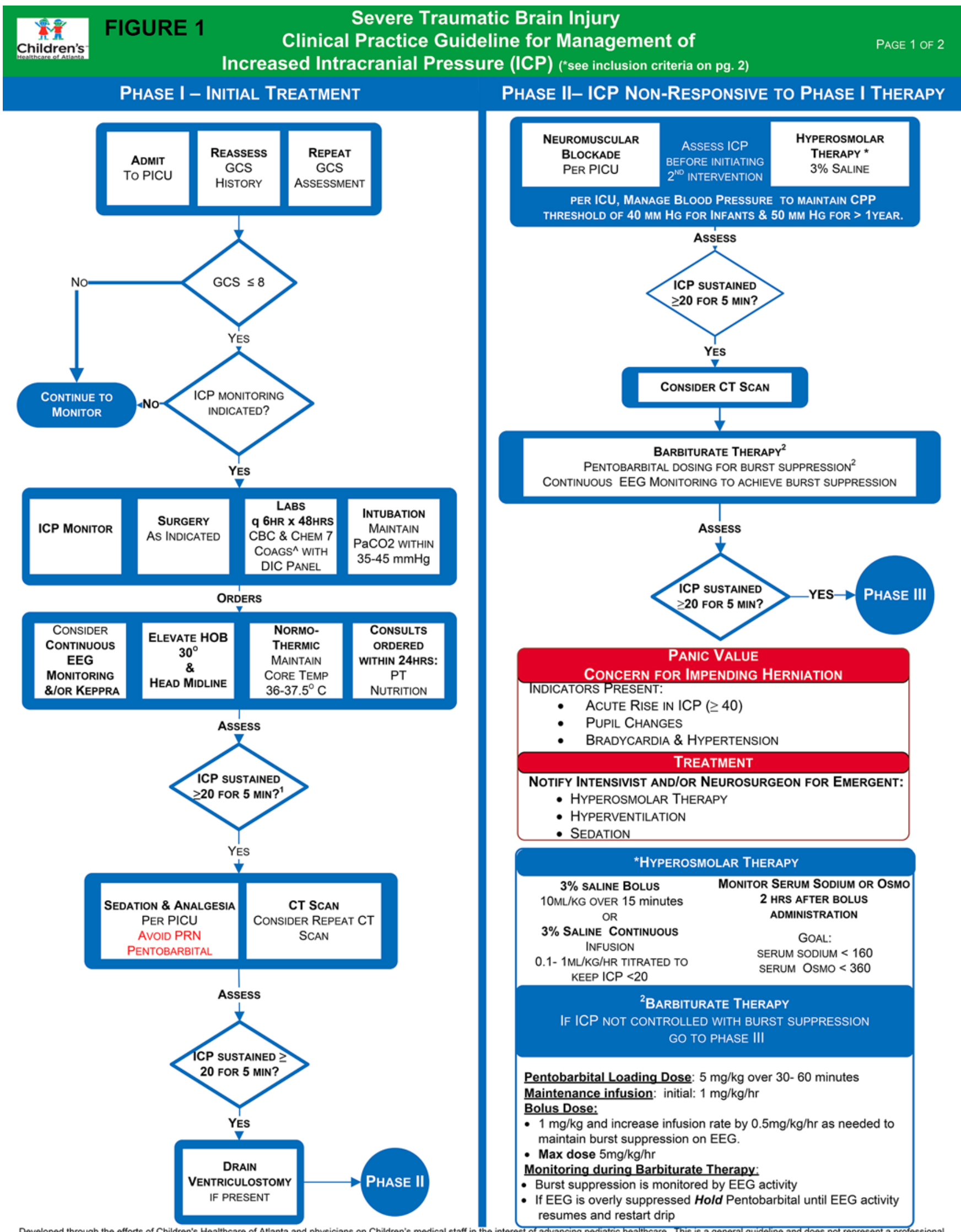

Developed through the efforts of Children's Healthcare of Atlanta and physicians on Children's medical staff in the interest of advancing pediatric healthcare. This is a general guideline and does not represent a professione care standard governing providers' obligation to patients. Ultimately the patient's physician must determine the most appropriate care. $\odot$ Children's Healthcare of Atlanta, Inc

FIG. 1. Children's Healthcare of Atlanta's TBI Pathway (Page 1 of 2). Copyright Children's Healthcare of Atlanta. Published with permission. Figure is available in color online only. 

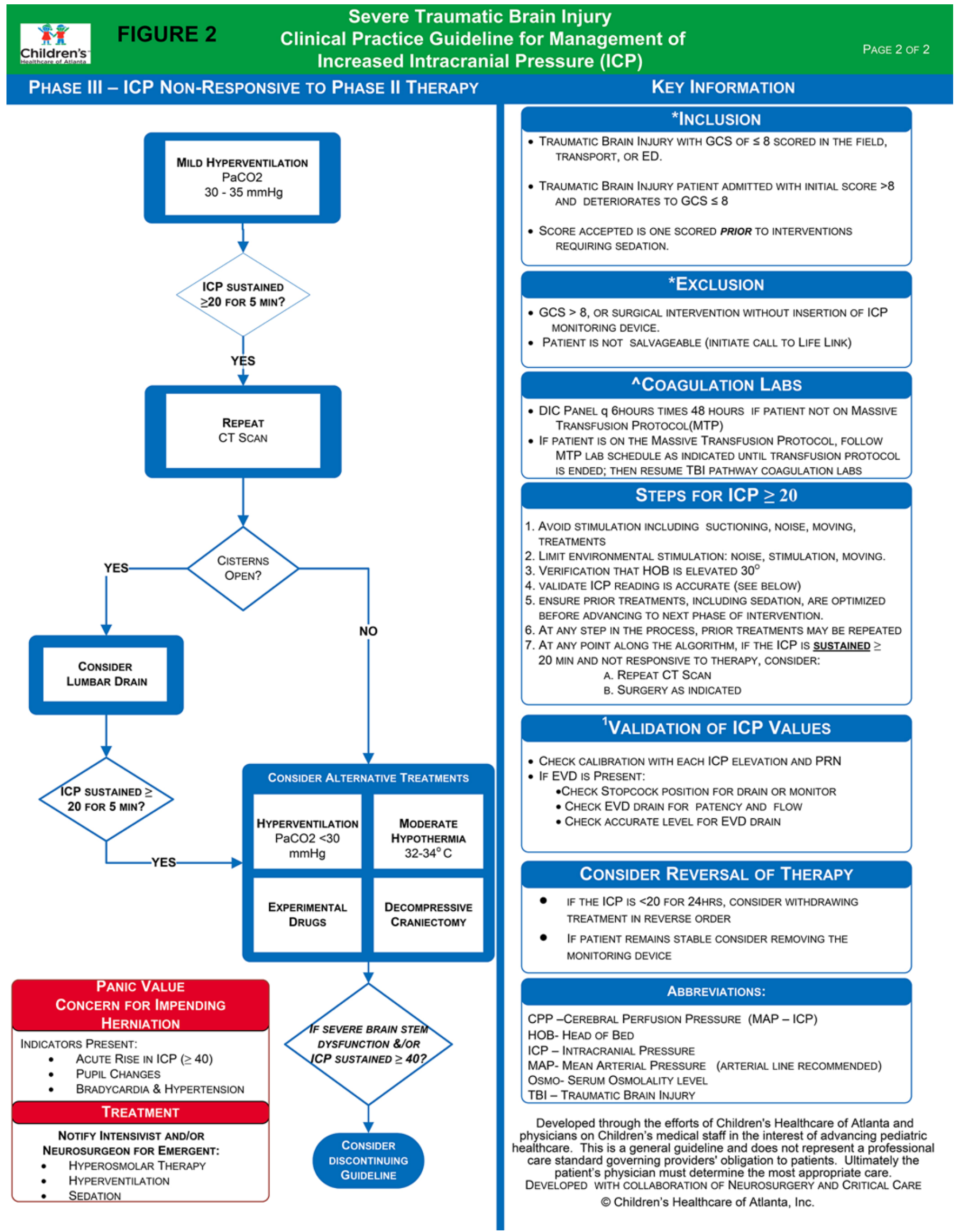

\section{*INCLUSION}
- Traumatic Brain INJURY WITH GCS OF $\leq 8$ SCORED IN THE FIELD, TRANSPORT, OR ED.
- TRAuMatic BRaIN INJURY PATIENT ADMITTED WITH INITIAL SCORE >8 AND DETERIORATES TO GCS $\leq 8$
- SCORE ACCEPTED IS ONE SCORED PRIOR TO INTERVENTIONS REQUIRING SEDATION.

\section{${ }^{\text {*EXCLUSION }}$}

- GCS > 8, OR SURGICAL INTERVENTION WITHOUT INSERTION OF ICP MONITORING DEVICE.

- Patient is not salvageable (Initiate call to Life Link)

\section{^COAGULATION LABS}

- Dic Panel q 6hours times 48 hours if PATIENT Not on Massive TRANSFUSION PROTOCOL(MTP)

- if patient is on the massive Transfusion Protocol, follow MTP LAB SCHEDULE AS INDICATED UNTIL TRANSFUSION PROTOCOL IS ENDED; THEN RESUME TBI PATHWAY COAGULATION LABS

\section{STEPS FOR ICP $\geq 20$}

1. AVOID STIMULATION INCLUDING SUCTIONING, NOISE, MOVING, TREATMENTS

2. LIMIT ENVIRONMENTAL STIMULATION: NOISE, STIMULATION, MOVING.

3. VERIFICATION THAT HOB IS ELEVATED $30^{\circ}$

4. VALIDATE ICP READING IS ACCURATE (SEE BELOW)

5. ENSURE PRIOR TREATMENTS, INCLUDING SEDATION, ARE OPTIMIZED BEFORE ADVANCING TO NEXT PHASE OF INTERVENTION.

6. AT ANY STEP IN THE PROCESS, PRIOR TREATMENTS MAY BE REPEATED

7. AT ANY POINT ALONG THE ALGORITHM, IF THE ICP IS SUSTAINED $\geq$

20 MIN AND NOT RESPONSIVE TO THERAPY, CONSIDER: A. REPEAT CT SCAN B. SURGERY AS INDICATED

\section{${ }^{1}$ VALIDATION OF ICP VALUES}

- Check calibration with each ICP Elevation and PRN - IF EVD is PRESENT:

-CHECK STOPCOCK POSITION FOR DRAIN OR MONITOR - CHECK EVD DRAIN FOR PATENCY AND FLow - CHECK ACCURATE LEVEL For EVD DRAIN

\section{CONSIDER REVERSAL OF THERAPY}

- IF THE ICP IS <20 FOR 24HRS, CONSIDER WITHDRAWING TREATMENT IN REVERSE ORDER

- if patient Remains Stable consider Removing the MONITORING DEVICE

\section{ABBREVIATIONS:}

CPP -CEREBRAL PERfusion PRESSURE (MAP - ICP)

HOB- HEAD OF BED

ICP - INTRACRANIAL PRESSURE

MAP- MEAN ARTERIAL PRESSURE (ARTERIAL LINE RECOMMENDED)

OSMO- SERUM OSMOLALITY LEVEL

TBI - TRAUMATIC BRAIN INJURY

Developed through the efforts of Children's Healthcare of Atlanta and physicians on Children's medical staff in the interest of advancing pediatric healthcare. This is a general guideline and does not represent a professional care standard governing providers' obligation to patients. Ultimately the patient's physician must determine the most appropriate care.

DEVELOPED WITH COLLABORATION OF NEUROSURGERY AND CRITICAL CARE (C) Children's Healthcare of Atlanta, Inc.

FIG. 2. Children's Healthcare of Atlanta's TBI Pathway (Page 2 of 2). Copyright Children's Healthcare of Atlanta. Published with permission. Figure is available in color online only. 
TABLE 1. Patient demographics obtained on admission

\begin{tabular}{lccc}
\hline \multicolumn{1}{c}{ Demographic } & Preguideline & Postguideline & $\mathrm{p}$ Value \\
\hline Total, no. & 71 & 121 & \\
\hline Male, no. (\%) & $42(59.1)$ & $84(69.4)$ & \\
\hline Mean age, yrs & 6.4 & 6.6 & 0.47 \\
\hline Mean Injury Severity Score & 25.8 & 23.8 & 0.31 \\
\hline Mean admission GCS score & 5.1 & 5.5 & 0.38 \\
\hline
\end{tabular}

pupil), or changes in vital signs indicative of a Cushing reflex (bradycardia and hypertension). For patients with ICPs $>40 \mathrm{~mm} \mathrm{Hg}$, the cerebrospinal fluid was drained, if an EVD was present, and the ICP was measured every hour. The neurosurgeon and intensivist would be automatically notified for any panic value.

\section{Definitions of Variables and Statistical Analysis}

Measures included patient demographics, admission characteristics, hospital length of stay (LOS), ventilator LOS, ICP type, need for neurosurgical procedure, critical ICP elevation time (percentage or total time that ICP was > $40 \mathrm{~mm} \mathrm{Hg}$ ), mortality, and survivor functionality measured by the Functional Independence for Children (WeeFIM) scores on rehabilitation admission and discharge. ${ }^{14}$

For patients with a Camino bolt only, information was captured electronically and continuously. When there was an EVD, information was measured hourly by the nurse or more frequently as needed based on clinical criteria such as pupillary changes or significant blood pressure changes (panic values). Elevated ICP was defined as sustained ICP $>20 \mathrm{~mm} \mathrm{Hg}$ for $>5$ minutes. The nursing staff typically did not document an ICP $>20 \mathrm{~mm} \mathrm{Hg}$, but $<40 \mathrm{~mm} \mathrm{Hg}$, if the patient was otherwise stable, unless it persisted $>5$ minutes. If all methods to decrease the ICP did not work (the monitor was recalibrated, head was midline, stimulation was reduced), then the elevated ICP was recorded.

In order to normalize ICPs for the length of time that an ICP monitor was in place, elevated ICPs were recorded as the percentage of time an ICP was elevated, relative to the total time the ICP monitor was in place.

Clinical findings were compared using Student t-tests (GNU PSPP; Free Software Foundation). For binary variables, Fisher's exact test was used. Statistical significance was defined as $\mathrm{p}<0.05$.

\section{Results}

\section{Patient Demographics and Admission Criteria}

A total of 71 patients were identified during the preguideline implementation period, and 121 patients were identified during the post-guideline implementation period. Admission characteristics (Table 1) between these groups were similar. The preguideline group was $59.1 \%$ male and the postimplemetation group was $69.4 \%$ male (p $=0.15$ ). Mean age was 6.4 years in the preguideline group and 6.6 years in the postguideline group $(\mathrm{p}=0.47)$. The mean Injury Severity Score of patients in the preguideline group was 25.8 versus 23.8 in the postguideline group ( $p$ $=0.31$ ). The mean admission GCS score for pre-guide-
TABLE 2. Hospital measures, pre- and postguideline

\begin{tabular}{|c|c|c|c|}
\hline Measure & Preguideline & Postguideline & $\begin{array}{c}p \\
\text { Value }\end{array}$ \\
\hline Mean inpatient LOS, days & 19.6 & 19.6 & 0.68 \\
\hline Mean ventilator LOS, days & 10.1 & 10.2 & 0.24 \\
\hline \multicolumn{4}{|l|}{ No. of patients (\%) } \\
\hline w/ a parenchymal electrode & $53(75)$ & $64(53)$ & 0.003 \\
\hline w/ an EVD & $38(54)$ & $83(69)$ & 0.037 \\
\hline Taken to surgery w/in $24 \mathrm{hrs}$ & $19(27)$ & $55(45)$ & 0.01 \\
\hline Time to surgery w/in $24 \mathrm{hrs}$, mins & 145 & 187 & 0.4 \\
\hline
\end{tabular}

line patients was 5.1 compared to 5.5 in the postguideline group $(\mathrm{p}=0.38)$.

\section{Hospital Measures and Patient Outcomes}

The mean hospital LOS was 19.6 days in both groups $(\mathrm{p}=0.68$; Table 2). The total number of days on a ventilator was also similar between groups-10.1 days in the preguideline group and 10.2 days for the postguideline group $(\mathrm{p}=0.24)$.

Given the inclusion criteria of the study, all patients had an ICP device, either a parenchymal electrode (Camino bolt) or an EVD. There was a greater use of Camino bolts to monitor ICP in the preguideline group (75\%) than in the postguideline group (53\%; $\mathrm{p}=0.003$; Table 2). In the postguideline group, there was a greater use of EVDs, as compared to the preguideline group (69\% vs $54 \%$, respectively; $\mathrm{p}=0.037$ ). In some cases (e.g., slit-like ventricles secondary to cerebral edema with intermittent cerebrospinal fluid drainage), an EVD and Camino bolt would be placed concurrently in the same patient. Additionally, some patients had a Camino bolt and an EVD at separate times during their ICU stays. In total, $27 \%$ of patients in the preimplementation group had both devices (19 of 71) and $22 \%$ of patients in the post-guideline implementation group had both (27 of 121).

The rates of patients undergoing a neurosurgical procedure within 24 hours of admission were greater in the postguideline group (45\%) than in the preguideline group $(27 \% ; \mathrm{p}=0.01$; Table 2$)$. Time to surgery from admission was similar in the two groups: 145 minutes in the preguideline group and 187 minutes in the postguideline group ( $\mathrm{p}=0.4$; Table 2$)$.

To examine ICP control, thresholds of ICP $>20 \mathrm{~mm} \mathrm{Hg}$ and ICP $>40 \mathrm{~mm} \mathrm{Hg}$ were used to determine the amount of time ICP was poorly controlled (Fig. 3). For patients in the preguideline group, ICPs $>20 \mathrm{~mm} \mathrm{Hg}$ were noted $26.3 \%$ of the time. ICP $>20 \mathrm{~mm} \mathrm{Hg}$ was significantly lower $(15 \%)$ in patients in the postguideline group $(\mathrm{p}=0.001)$. Similarly, ICPs $>40 \mathrm{~mm} \mathrm{Hg}$ were noted in the preguideline group $14.7 \%$ of the time as compared with $6.4 \%$ of the time in the postguideline group ( $p<0.001)$.

The mortality rate in the preguideline group was $32 \%$ and that in the postguideline group was $19 \%(\mathrm{p}=0.04$; Fig. 4). The WeeFIM scores for survivors were similar between the two groups when comparing admission score, the discharge from rehabilitation score, and the difference between the two (Table 3). 


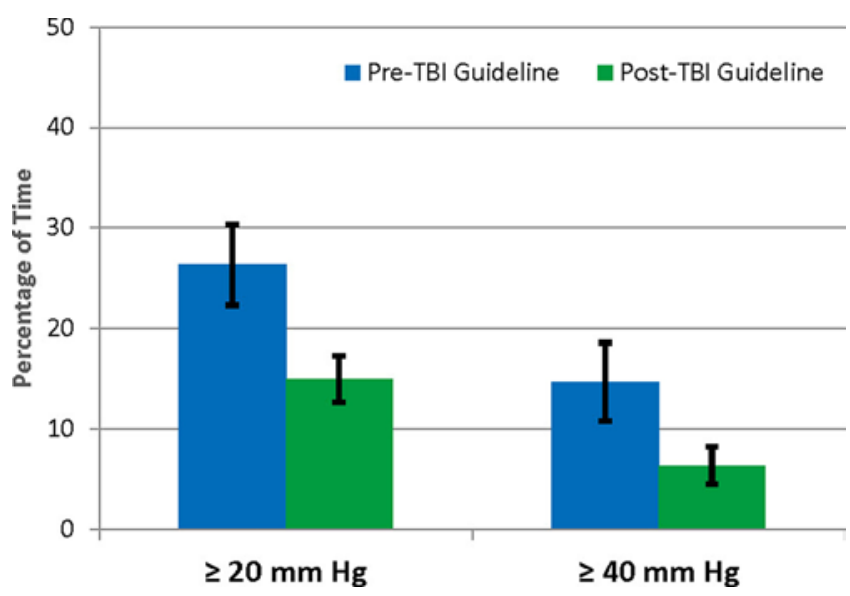

FIG. 3. The percentage of total time patients' ICP was $>20 \mathrm{~mm} \mathrm{Hg}$ or 40 $\mathrm{mm} \mathrm{Hg}$ stratified by treatment before or after implementation of guidelines for severe TBI. Figure is available in color online only.

\section{Discussion}

Based on current estimates, severe pediatric TBI is associated with a $20 \%$ mortality rate, with a 6 -month unfavorable outcome rate of $50.6 \% .^{18}$ Outcomes have not improved much in the last decade, with overall rates of TBIrelated hospitalizations remaining relatively stable $(82.7$ per 100,000 in 2001 and 91.7 per 100,000 in 2010) and TBI-related deaths decreasing just slightly from 18.5 per 100,000 in 2001 to 17.1 per 100,000 in $2010 .{ }^{5}$ Most survivors of severe TBI have long-term intellectual deficits and a reduced quality of life. ${ }^{17}$

In pediatric TBI, outcomes are predicted by the severity of initial head and extracranial trauma, ${ }^{28}$ prevention of secondary injuries, ${ }^{1,17}$ and access to timely, high-quality care. ${ }^{20,24}$ Increasingly, health systems are implementing practice guidelines for the acute care of severe TBI in an attempt to improve outcomes. ${ }^{15,17}$

This study compared outcomes between patients who had ICPs measured before and after implementation of guidelines. With implementation of an ICU guideline for the management of severe pediatric TBI at Children's, overall our use of ICP monitoring devices increased from $34.2 \%$ to $58 \%$ in patients with a GCS score $\leq 8$. Patients with a monitoring device treated in the post-guideline implementation group spent significantly less time with elevated ICP (> $20 \mathrm{~mm} \mathrm{Hg}$ and $>40 \mathrm{~mm} \mathrm{Hg}$ ). Additionally, the mortality rate significantly declined in the post-guideline implementation group compared to the pre-guideline implementation group, although measures of pediatric functional independence among survivors were similar.

Known secondary injuries resulting from the pathophysiological cascade of events following TBI are complex. Prolonged intracranial hypertension is known to compound and intensify the resulting cellular and extracellular alterations and cerebrovascular dysfunction. By reducing the time patients had elevated ICP, this guideline allowed timely medical and/or surgical treatment to be instituted, thus minimizing the deleterious effects of sustained intracranial hypertension. We believe that severe TBI guideline initiation and adherence streamlined prompt point-of-care

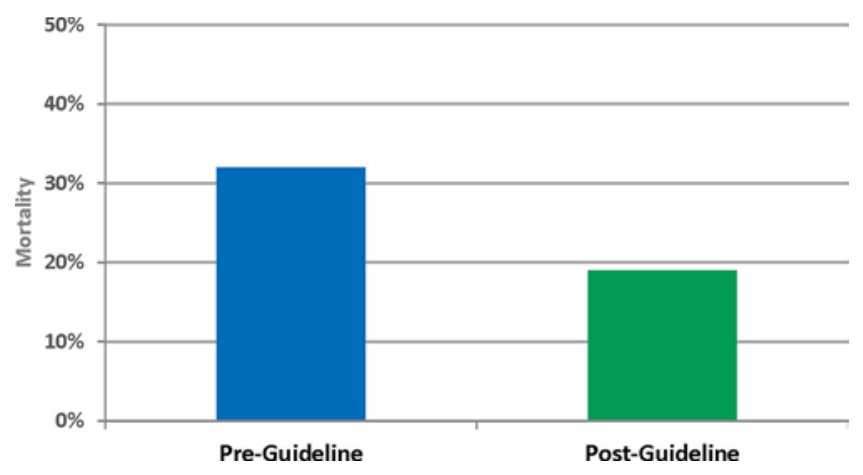

FIG. 4. The mortality rates stratified by treatment before or after implementation of guidelines for severe TBI. Figure is available in color online only.

interventions. This in turn resulted in shortened time with intracranial hypertension. This may have been responsible for the improved outcomes.

Our results are consistent with the findings of other groups suggesting that initiation of standardized ICU care based on guidelines, including ICP monitoring, are associated with improvement in cases of severe TBI. $8,15,17,22,24,26$ Despite this growing body of literature, institutional practice variation may limit direct comparison between studies.

\section{Practice Variation}

The Brain Trauma Foundation's 2003 Pediatric TBI Guidelines ${ }^{4}$ represented the first interdisciplinary guidance on evidence-based acute care for infants and children with severe TBI. The 2014 update to the initial guidelines included 14 treatment recommendations believed to be associated with improved outcomes, although the evidence at the time was insufficient to support a level I recommendation. ${ }^{11,13}$

This lack of strong recommendations in the care of pediatric severe TBI may contribute to practice variability and the lack of broadly applicable clinical guidelines for treatment of children with severe TBI. ${ }^{12}$ The growing literature shows that evidence-informed practice guidelines do make clinical differences within individual institutions. However, a survey of 32 clinical sites treating pediatric severe TBI as part of the ADAPT Trial found dramatic variation between and within clinical sites with regard to goals of ICP management, mitigation of secondary injuries, and metabolic support. ${ }^{12}$

This variation in the bundle of care for managing severe TBI is notable because, unlike other conditions, there is no single intervention that can cure TBI or associated secondary injuries. The present study did reduce practice variability for patients receiving care for severe TBI across two tertiary care sites within the Children's system. Baseline use of guidelines averaged $34.2 \%$ in 2010, and improved to $100 \%$ during the postguideline period. We believe that the statistically significant outcomes-less time with elevated ICP (both for $>20 \mathrm{~mm} \mathrm{Hg}$ and $>40 \mathrm{~mm} \mathrm{Hg}$ ) and improved survival-may be due to the reduced practice variability among neurosurgery and ICU attending physicians involved in the care of these patients. 
TABLE 3. Patient outcomes, pre- and postguideline

\begin{tabular}{lccc}
\hline \multicolumn{1}{c}{ Outcome Variable } & Preguideline & Postguideline & p Value \\
\hline Mortality, no. (\%) & $23(32)$ & $23(19)$ & 0.04 \\
\hline WeeFIM & & & \\
\hline Admission score & 30.25 & 32.8 & 0.4 \\
\hline$\quad$ Discharge score & 57.6 & 58.9 & 0.9 \\
\hline $\begin{array}{l}\text { Difference from admission } \\
\text { to discharge }\end{array}$ & 27.3 & 26.4 & 0.7 \\
\hline
\end{tabular}

It remains unclear if the lack of progress in identifying TBI-specific treatment is due to a lack of understanding of the pathophysiology of the condition or possibly to a failure to reproduce potentially promising interventions because of practice variation between institutions. ${ }^{12}$ Standardizing care around clinical guidelines could enhance trials by limiting the number of variables. This could be particularly important in pediatric TBI research, where improved outcomes have been challenged by the lack of translation of adult findings to younger populations.

\section{Limitations and Directions for Future Study}

This guideline was viewed as a "living" document and was deemed adaptable to accommodate research purposes (e.g., addition of hematological panel to address research questions regarding traumatic coagulopathy) or new evidence. While it was beneficial for our institution to adapt the protocol based on emerging evidence (modifications were incorporated based on new literature, including papers showing the beneficial effect of early nutrition as well as the removal of the diuretic mannitol because of consensus within the institution), this flexibility may hamper precise reproducibility in other settings.

We also recognize limitations in retrospective comparisons and in the focus on short-term outcome measures. Although reduction in time of intracranial hypertension is suspected to have had a positive effect on outcome, how this influenced the pathophysiology following TBI is not known. We suggest that future studies assess longer-term outcomes, the implementation of such a guideline simultaneously at multiple institutions, and the impact of guideline implementation on cost.

However, despite these limitations, instituting an ICPbased treatment guideline meaningfully improved clinical outcomes in children with severe TBI. Strengths of the guideline development and implementation included adhering to evidence or consensus when evidence was incomplete, engaging all stakeholders from the beginning, standardizing care, and continually monitoring for guideline compliance.

\section{Conclusions}

A multidisciplinary effort to develop, implement, and monitor a comprehensive, severe pediatric TBI care guideline, as well as educating staff, was associated with improved outcomes. ICP monitoring is a critical component to the guideline and to severe TBI care, as control of ICP lessens secondary complications, which are known to hamper recovery from severe TBI. This guideline could serve as a guide for other institutes looking to reduce institutional practice variability in the treatment of severe pediatric TBI.

\section{References}

1. Agrawal S, Branco RG: Neuroprotective measures in children with traumatic brain injury. World J Crit Care Med 5:36-46, 2016

2. Aiolfi A, Benjamin E, Khor D, Inaba K, Lam L, Demetriades $\mathrm{D}$ : Brain Trauma Foundation guidelines for intracranial pressure monitoring: compliance and effect on outcome. World J Surg 41:1543-1549, 2017

3. Alkhoury F, Kyriakides TC: Intracranial pressure monitoring in children with severe traumatic brain injury: National trauma data bank-based review of outcomes. JAMA Surg 149:544-548, 2014

4. Carney NA, Chesnut R, Kochanek PM: Guidelines for the acute medical management of severe traumatic brain injury in infants, children, and adolescents. Pediatr Crit Care Med 4 (3 Suppl):S1-S75, 2003

5. Centers for Disease Control and Prevention: Rates of TBIrelated emergency department visits, hospitalizations, and deaths - United States, 2001-2010. CDC.gov. (https://www. cdc.gov/traumaticbraininjury/data/rates.html) [Accessed March 19, 2018]

6. Cuschieri J, Johnson JL, Sperry J, West MA, Moore EE, Minei JP, et al: Benchmarking outcomes in the critically injured trauma patient and the effect of implementing standard operating procedures. Ann Surg 255:993-999, 2012

7. Dinsmore J: Traumatic brain injury: an evidence-based review of management. Contin Educ Anaesth Crit Care Pain 13:189-195, 2013

8. Fakhry SM, Trask AL, Waller MA, Watts DD: Management of brain-injured patients by an evidence-based medicine protocol improves outcomes and decreases hospital charges. J Trauma 56:492-500, 2004

9. Jagannathan J, Okonkwo DO, Yeoh HK, Dumont AS, Saulle $\mathrm{D}$, Haizlip J, et al: Long-term outcomes and prognostic factors in pediatric patients with severe traumatic brain injury and elevated intracranial pressure. J Neurosurg Pediatr 2:240-249, 2008

10. Kannan N, Ramaiah R, Vavilala MS: Pediatric neurotrauma. Int J Crit Illn Inj Sci 4:131-137, 2014

11. Kochanek PM, Carney N, Adelson PD, Ashwal S, Bell MJ, Bratton S, et al: Guidelines for the acute medical management of severe traumatic brain injury in infants, children, and adolescents-second edition. Pediatr Crit Care Med 13 (1 Suppl):S1-S82, 2012

12. Larsen GY, Schober M, Fabio A, Wisniewski SR, Grant MJ, Shafi N, et al: Structure, process, and culture differences of pediatric trauma centers participating in an international comparative effectiveness study of children with severe traumatic brain injury. Neurocrit Care 24:353-360, 2016

13. Lingsma HF, Roozenbeek B, Li B, Lu J, Weir J, Butcher I, et al: Large between-center differences in outcome after moderate and severe traumatic brain injury in the international mission on prognosis and clinical trial design in traumatic brain injury (IMPACT) study. Neurosurgery 68:601-608, 2011

14. McCabe MA, Granger CV: Content validity of a pediatric functional independence measure. Appl Nurs Res 3:120122,1990

15. O'Lynnger TM, Shannon CN, Le TM, Greeno A, Chung D, Lamb FS, et al: Standardizing ICU management of pediatric traumatic brain injury is associated with improved outcomes at discharge. J Neurosurg Pediatr 17:19-26, 2016

16. Peterson ED, Bynum DZ, Roe MT: Association of evidencebased care processes and outcomes among patients with acute coronary syndromes: performance matters. J Cardiovasc Nurs 23:50-55, 2008 
17. Pineda JA, Leonard JR, Mazotas IG, Noetzel M, Limbrick DD, Keller MS, et al: Effect of implementation of a paediatric neurocritical care programme on outcomes after severe traumatic brain injury: a retrospective cohort study. Lancet Neurol 12:45-52, 2013

18. Popernack ML, Gray N, Reuter-Rice K: Moderate-to-severe traumatic brain injury in children: Complications and rehabilitation strategies. J Pediatr Health Care 29:e1-e7, 2015

19. Roumeliotis N, Pettersen G, Crevier L, Émeriaud G: ICP monitoring in children: why are we not adhering to guidelines? Childs Nerv Syst 31:2011-2014, 2015

20. Rusnak M, Janciak I, Majdan M, Wilbacher I, Mauritz W: Severe traumatic brain injury in Austria VI: effects of guideline-based management. Wien Klin Wochenschr 119:64-71, 2007

21. Schwentner L, Wöckel A, König J, Janni W, Ebner F, Blettner $\mathrm{M}$, et al: Adherence to treatment guidelines and survival in triple-negative breast cancer: a retrospective multi-center cohort study with 9,156 patients. BMC Cancer 13:487, 2013

22. Stein SC, Georgoff P, Meghan S, Mirza KL, El Falaky OM: Relationship of aggressive monitoring and treatment to improved outcomes in severe traumatic brain injury. J Neurosurg 112:1105-1112, 2010

23. Talving P, Karamanos E, Teixeira PG, Skiada D, Lam L, Belzberg $\mathrm{H}$, et al: Intracranial pressure monitoring in severe head injury: compliance with Brain Trauma Foundation guidelines and effect on outcomes: a prospective study. J Neurosurg 119:1248-1254, 2013

24. Vavilala MS, Kernic MA, Wang J, Kannan N, Mink RB, Wainwright MS, et al: Acute care clinical indicators associated with discharge outcomes in children with severe traumatic brain injury. Crit Care Med 42:2258-2266, 2014

25. Visser BC, Ma Y, Zak Y, Poultsides GA, Norton JA, Rhoads KF: Failure to comply with NCCN guidelines for the management of pancreatic cancer compromises outcomes. HPB 14:539-547, 2012

26. Wainwright MS, Hansen G, Piantino J: Pediatric neurocritical care in the 21st century: from empiricism to evidence. Curr Opin Crit Care 22:106-112, 2016

27. White JRM, Farukhi Z, Bull C, Christensen J, Gordon T, Paidas C, et al: Predictors of outcome in severely headinjured children. Crit Care Med 29:534-540, 2001

28. Yue JK, Winkler EA, Burke JF, Chan AK, Dhall SS, Berger
MS, et al: Pediatric sports-related traumatic brain injury in United States trauma centers. Neurosurg Focus 40(4):E3, 2016

\section{Disclosures}

The authors report no conflict of interest concerning the materials or methods used in this study or the findings specified in this paper.

\section{Author Contributions}

Conception and design: Reisner, Chern, Walson, Tillman, Petrillo-Albarano, Vats. Acquisition of data: Reisner, Chern, Walson, Tillman, Sribnick, Blackwell, Vats. Analysis and interpretation of data: Reisner, Chern, Petrillo-Albarano, Sribnick, Blackwell, Suskin. Drafting the article: Reisner, Chern, Walson, Petrillo-Albarano, Sribnick, Vats. Critically revising the article: all authors. Reviewed submitted version of manuscript: Reisner, Chern, Walson, Tillman, Sribnick, Blackwell, Suskin, Vats. Approved the final version of the manuscript on behalf of all authors: Reisner. Statistical analysis: Reisner, Chern, Blackwell, Vats. Administrative/technical/material support: Reisner, PetrilloAlbarano, Sribnick, Blackwell. Study supervision: Chern, Tillman, Vats.

\section{Supplemental Information \\ Previous Presentations}

Portions of this work were presented in oral form at the Society of Critical Care Medicine 44th Critical Care Congress, Phoenix, AZ, January 17-21, 2015, where it was nominated for a best presentation award; in oral form at the British Neurosurgical Society Meeting, Southampton, United Kingdom, April 2015, and it was then published as proceedings in British Journal of Neurosurgery 29(2):144-145, April 2015; in oral form at the Southern Neurosurgery Society, San Antonio, TX, March 3-5, 2016; and as a podium presentation at the 2016 Annual Meeting of the Pediatric Trauma Society, Nashville, TN, November 11-12, 2016.

\section{Correspondence}

Andrew Reisner: Children's Healthcare of Atlanta, GA. andrew. reisner@choa.org. 